\title{
EFFECT OF SOCIO-COGNITIVE SKILLS TRAINING ON AGGRESSIVE SECONDARY SCHOOL ADOLESCENTS IN ANAMBRA STATE NIGERIA
}

\author{
Mercy Aku Anagbogu*, Christopher Amobi Nwankwo* \\ \& \\ Ifeanyi Mathew Azuji* \\ http://dx.doi.org/10.4314/og.v16i1.5
}

\begin{abstract}
Aggressive behaviour is a serious malady to students, especially those in their adolescent stage. This study investigated the effect of Sociocognitive skills training on aggressive secondary school adolescents in Anambra State, Nigeria. One research question guided the study and two null hypotheses tested at 0.05 level of significance. The design for the study is quasi-experimental, non-randomised pre-test and post-test, control group design. The population of the study was 323 senior secondary school adolescents with high aggressive behaviour in Anambra State. A sample size of 32 adolescents were purposively drawn from two schools with the highest number of adolescents with high aggressive behaviour and used for the study. Instrument for data collection was adopted from Buss-Perry Aggression Questionnaire (BPAQ). The internal consistency reliability coefficient for Nigeria sample is 0.80 . The completed instruments were scored following the scoring instructions provided in the BPAQ manual. Mean scores were used to answer the research question, while the null hypotheses were tested using Analysis of Co-variance (ANCOVA). The norm of 70.25 provided in BPAQ guided the decision. The finding of the study revealed that socio-cognitive skills' training was effective in reducing aggressive behaviour of secondary school adolescents. The findings further revealed that the difference in the effect of socio-cognitive skills training on aggressive secondary school adolescents was significant when compared with those in the control group. Based on the findings it was recommended that the practicing counsellors and therapists should adopt the use of the technique in managing aggressive behaviours of secondary school adolescents.
\end{abstract}

Keywords: Aggressive Behaviour, Secondary School Adolescents, Socio-cognitive Skills, Training 
Anagbogu, Nwankwo \& Azuji: The effect of Socio-Cognitive ...

\section{Introduction}

Aggressive behaviour is a misconduct which is today a worrisome phenomenon as many schools, families and job-related settings now seem to have a significant number of people with such hostile and destructive behaviour. Thus, the issue has attracted the attention of school counsellors, researchers and other stakeholders within and outside educational settings to find a way of dealing with the aggressive issue.

Aggressive behaviour is perceived to be exhibited frequently and more intensely among adolescents and young adults with many serious consequences for both the aggressor and people around them. Injuries to peers, teachers and other staff in school and family members as a result of aggressive behaviours are not uncommon. These injuries tend to lead to significant costs to both the school and the family. Also, the social, economic and public health burden created by the perpetration of aggressive acts as noted by Centres of Disease Control and Prevention (2013) is profound. So, based on the nature of aggressive behaviour, especially as it concerns adolescents, the use of effective counselling techniques to modify such maladaptive behaviour represents a crucial step to curbing incidents of its occurrences and by extension reducing conflict at home, school and the larger society.

Aggressive behaviour has been differently defined. According to Zirpoli (2014), aggressive behaviour is seen as any form of conduct or actions by an individual, which is intended to cause pain, suffering and damage to another person. Gould, Grant, Gould, and Jensen (2008) also see aggressive behaviour as a form of actions characterized by an assault or attack by one person on another. From the above definitions, aggressive behaviour is understood to encompass variety of behaviours. These behaviours range from mild verbal aggressive conducts usually exhibited from elementary to secondary school years, such as starting rumours, excluding others during plays, and arguing, to bullying, physical fighting, robbery, rape and other unwholesome behaviours with the sole intent to harm another. So, in the context of this study, aggressive behaviour is seen as a category of behaviours; physical, verbal or relational that is exhibited by adolescents and which causes or threatens to harm others. 
Aggressive behaviour comes in different forms; it could be physical, verbal or relational. It could come in the form of physical or verbal belligerence between couples, siblings, or parents who sometimes tend to use it as a corrective measure towards their children. Today one could see children killing fellow children, carrying knives, sharp objects, and even guns in the name of cultism. Likewise, the behaviour is not spared in various meeting places such as village meetings and even unexpected places like the hallowed chambers of the law-making bodies. Yet, the occurrence of aggressive behaviour seems more in schools today. For instance, Shekarey, Ladarni and Rostami (2013) in their study acknowledge that aggressive behaviours are common occurrences in today's schools, even among secondary school adolescents. The reason could be attributed to their developmental characteristics whereby they tend to go into risky anti-social behaviour and try-out experiences which often lead to mistakes.

More so, these adolescents are mostly in secondary school level of education which is a type of education that coincides with the adolescent stage of development. Meyers (2016) holds that adolescents tend to manifest aggressive behaviours more at this stage. This may not be far from the reality as there are reports today of decadent behaviours such as bullying, molestation of fellow students, disruptive competitions (even during sporting activities) and other forms of abnormal behaviours capable of inflicting both psychological and physical pain among the school adolescents.

In like manner, Aluede (2011) in his study on managing bullying problems in Nigerian secondary schools, stresses that violence in schools has become an issue that is gradually becoming more prominent over the years. For that same reason, news and articles about violent activities within the school setting has remained on steady increase. For example, it is no longer a rare or strange thing to see fighting among students that may lead to the destruction of school properties; where junior students are being bullied by senior students; where students are threatening their fellow students, teachers and even their parents at home. These are various forms of aggressive acts perpetrated mostly by young adolescents between the ages of 13 and 21 . 
Anagbogu, Nwankwo \& Azuji: The effect of Socio-Cognitive ...

Adolescents are young people in their teenage years, usually seen as the period that begins with the onset of puberty and ends somewhere around age thirteen to twenty-three, depending on the societal ethos and onset of puberty (sexual maturity stage which usually takes place on or before the adolescence stage). This process of sexual maturity according to World Health Organisation (WHO, 2014) involves biological, cognitive and social changes. Biological changes involve physical development; cognitive changes comprise thought, intelligence, and language; and social changes involves the adolescents' emotions, personality, and their relationships with other people in a social context. In the context of this study however, adolescents are persons in the developmental period, between 13 and 21 years of age, which is a period that spans from onset of puberty to the beginning of adulthood.

Studies such as Agbakwuru and Ugwueze (2014) and Nnodum (2010) have decried the persistent effects of aggressive behaviours especially in schools and the failure of the conventional approach to counselling in addressing aggressive problems. They thus suggest the use of more effective psychological techniques in treatment of aggressive acts and prevention of future aggressive conducts. In the same way, a study by Terzian, Hamilton, and Ling (2011) which centres on different prevention program that addresses such expressive behaviours like aggression; was more of a pointer indicating that aggressive adolescents need specific sets of sociocognitive competencies to function well in a group or within the society where they may find themselves.

Individual differences in social information processing skills would likely help explain why people confronted with the same social situation may choose to act in very different ways. For example, two children may be teased by a peer, one child may perceive this as harmless play and may laugh over it, whereas another child may interpret this as unpleasant and threatening and may choose to act aggressively toward the peer. Thus, this is in line with Jean, Bergeron, Thivierge and Simard (2010) observation that such distortions or deficiencies in social information processing may lead to a maladaptive behaviour as aggression. Jean et al. therefore suggest socio-cognitive skills training for individuals with such behaviour, bearing in mind that the impairment of both basic 
cognition and social cognition is a well-established feature of aggressive behaviour.

Considering the amount of evidence that have shown the link between neurocognition, and especially social cognition with regard to functional outcome, a number of groups have developed new treatments skills to improve basic cognitive deficits, as well as social cognition. Socio-cognitive skills according to Horan, Kern, Tripp, Hellemann, Wynna, Bell, Marder, and Green (2011) include: a. emotional processing which involves educational presentations focused on defining six basic emotions (happy, sad, angry, disgusted, afraid, and surprised), identifying those emotions on the face and in the voice, and reviewing non-social situations communication. b. attributional bias which involves understanding suspiciousness as an emotion. c. mentalizing which focuses on integrating the various emotional and social cues covered to understand and adaptively respond to others' beliefs and intentions and d. social perceptions which covers non-verbal social cues and social contexts that typically lead people to experience different emotions (example; social norms, posture, eye contact, hand gestures, status differences between interaction partners, emotional intensity, sounds that convey understanding).

One major goal of socio-cognitive skills training as observed by Babakhani (2011) is teaching persons who have emotional problems about the verbal, nonverbal, as well as cognitive aspect of behaviours involved in social interaction. Such people could be said to be behaviourally impaired or lacking in certain social and cognitive competence. This researcher consequently describes Sociocognitive skills training (SCST) in the context of this study as a form of behavioural therapeutic training that focuses on improving cognitive and meta-cognitive impairments that interfere with normal social functioning in adolescents, especially those in schools. SCST as used in this study therefore is designed towards enhancing the process of acquiring knowledge by secondary school adolescents' use of reasoning, intuition, or perception through training.

The development of socio-cognitive treatments according to Kern, Glynn, Horan, Marder (2009) involves identifying key determinants of individuals' poor functioning and testing the effectiveness of the techniques designed to improve those 
Anagbogu, Nwankwo \& Azuji: The effect of Socio-Cognitive ...

behavioural clues. A good example is Horan et al. (2011) study which combined a variety of novel training exercises and materials to target emotion identification, social perception, attribution bias, and mentalizing. The SCST group demonstrated a significant improvement in facial affect perception that was independent of symptoms and not present in the control group, thereby supporting the feasibility and efficacy of such targeted training programme in clients with behavioural disorders.

Since aggressive behaviour results from one not being able to manage his or her emotion, which is potentially destructive for both boys and girls, Socio-Cognitive Skills Training could help individuals change their mental orientation about themselves, communicate their beings, moods and thoughts reasonably and improve their self-consciousness. In view of this, this study is set out to achieve the following; to examine the effects of the techniques (socio-cognitive skills training and self-instruction technique) on aggressive secondary school adolescents, and to determine which of the two techniques is more effective on aggressive secondary school adolescents.

Aggression is a serious behaviour problem that could place the students, and the entire school, home or community at risk. In Anambra State for instance, increasing high rates of aggressive behaviours is consistently given in to several threats to school safety, with much implication for students' mental wellbeing and academic outcomes. The schools as it is today seem unsafe. The situation looks so unpleasant such that parents, teachers and counsellors, including this researcher are worried and in dire need of a way out.

In response to the worries and the need to curb the occurrence of aggressive behaviours in schools, teachers tend to employ a variety of approaches in addressing cases of aggression, some of this measures are punitive and some, non-punitive. However, none has been able to address the problem. As a consequence of these undesirable outcomes, comes the need for professional counsellors to take appropriate measures to address the lingering problem. The challenge to counsellors and scholars in the field of education which has necessitated the need for this study to investigate the effects of two psychological treatment approaches 
that could be used to reduce the manifestation of aggressive behaviour among students.

The effect of Socio-cognitive skills training in handling maladaptive behaviours is perceived to be effective as observed in literature. This researcher thus believes that since these approaches were effective in handling other maladaptive problems, they would likely be effective in curbing aggressive behaviour of secondary school adolescents, especially those in Anambra State.Consequently, this study investigates the effect of socio-cognitive skills training on aggressive behaviour of secondary school adolescents in Anambra State.

\section{Purpose of the Study}

The purpose of this study is to investigate the effect of SocioCognitive Skills Training on secondary school adolescents' aggressive behaviour in Anambra State. Specifically, the study sought to determine:

1. The effect of Socio-Cognitive Skills Training on aggressive secondary school adolescents.

2. The effectiveness of Socio-Cognitive Skills Training on aggressive male and female secondary school adolescents.

\section{Research Questions}

The following research questions served as a guide for study-:

1. What is the effect of Socio-Cognitive Skills Training on the aggressive behaviours of secondary school adolescents when compared to those in the control group using their pre-test and post-test scores?

2. What is the effectiveness of Socio-Cognitive Skills Training on aggressive behaviours of male and female secondary school adolescents using their pretest and posttest scores?

\section{Hypotheses}

The following null hypotheses guided the study, and were tested at the 0.05 level of significance.

1. The effect of Socio-Cognitive Skills Training on the aggressive behaviours of secondary school adolescents when 
Anagbogu, Nwankwo \& Azuji: The effect of Socio-Cognitive ...

compared to those in the control group using their post-test scores is not significant.

2. There is no significant difference in the effects of SocioCognitive Skills Training on aggressive male and female secondary school adolescents using their post-test mean scores.

\section{Method}

\section{Research Design}

This study is a non-randomized pre-test, post-test, control group quasi-experimental research. The study involved two treatment conditions (Experimental and Control group) for the adolescents identified with aggressive behaviour. The students were randomly assigned to one of the two treatment conditions after the baseline assessment.

\section{Research Setting}

The study was conducted in Anambra State, located in the South East Geo-Political Zone of Nigeria. There have been records of aggressive acts such that educators are often confronted by angry, defiant adolescents in schools which were the reason why this study was conducted in the area.

\section{Participants}

The sample of the study comprised 32 adolescents purposively selected from a population of 325 adolescents with record of high aggressive behaviours in Anambra State. The selection was based on the severity of their aggressive behaviour indicated by their pre-test scores obtained through administration of the Buss-Perry Aggressive Scale. Two schools where the adolescents have records of more severe aggressive behaviour were selected for the study. The number of identified aggressive adolescents in each of the selected schools is 15 and 17 , totalling 32 adolescents.

\section{Instrument for Data Collection}

In order to measure aggressive personality traits, the researchers adopted Buss-Perry Aggression Questionnaire (BPAQ) for the study. The scale consists of four subscales to measure different types of 
aggressive behaviours: physical aggression, verbal aggression, anger, and hostility. This questionnaire comprised of 29 self-report items. It asks respondents to rate items on a scale from one to five based on whether the statement is "extremely uncharacteristic" or "extremely characteristic" of them.

The instrument, BPAQ was developed and validated by Buss and Perry in 1992. It was however revalidated and used in Nigeria. The internal consistency reliability coefficients were as follows: Physical Aggression, $\alpha=0.85$; Verbal Aggression, $\alpha=0.72$; Anger, $\alpha=0.83$ and Hostility, $\alpha=0.77$, with the internal consistency being $\alpha=0.89$. Test-retest reliability for the subscales and total score ranged from $\alpha$ $=0.72$ to $\alpha=0.80$.

\section{Experimental Procedure}

The researchers obtained the approval of the schools' principals for carrying on with the research through a consent letter that was given to the principals. The experimental training sessions and the control group conventional counselling sessions then took place at the two schools chosen for the study. The researcher, with the assistance of the guidance counsellors in the schools conducted a training programme which held for eight weeks for both the treatment and control group. The treatment sessions were carried out in the school's counselling centres. The day and time for each group's training was established and maintained throughout the treatment. Each training session lasted for 45 minutes using the counselling scheduled periods as specified by the schools. The participants in the experimental groups were trained on Socio-cognitive Skills while those in the control group were received the usual conventional group counselling. Each of the groups received training for the eight weeks. After the eight weeks of treatment and conventional counselling, the Buss-Perry Aggressive Questionnaire was readministered on all the participants in both the experimental and control groups. The scores obtained were stared as the post-test. The post-test scores along with the earlier elicited pre-test scores were then collated and were statistically analysed. 
Anagbogu, Nwankwo \& Azuji: The effect of Socio-Cognitive ...

\section{Method of Data Analysis}

The completed instruments were scored following the scoring instructions provided in the Buss-Perry Aggression Questionnaire (BPAQ) manual. The data relating to the research questions were analysed using statistical Mean. The data relating to the null hypotheses were tested using the Analysis of Co-variance (ANCOVA). When the post-test mean score of a group is below the norm of 70.27, the treatment technique for that group is considered "effective", while scores above the norm is "not effective". For the null hypotheses, when the pvalue is less than 0.05 level of significance the null hypotheses is rejected, but when the pvalue is greater than the 0.05 level of significance the null hypothesis is not rejected.

\section{Results}

\section{Research Question 1}

What is the effect of Socio-cognitive training on the aggressive behaviours of secondary school students when compared with those treated with conventional counselling using their pre-test and posttest scores?

Table 1: Pre-test and Post-test aggression behaviour mean scores of adolescents treated with socio-cognitive training skills and those treated with conventional counselling $($ Norm $=70.27)$

\begin{tabular}{lccccc}
\hline $\begin{array}{l}\text { Source of } \\
\text { variation }\end{array}$ & $\mathbf{N}$ & $\begin{array}{l}\text { Pre-test } \\
\text { Mean }\end{array}$ & $\begin{array}{l}\text { Post-test } \\
\text { Mean }\end{array}$ & $\begin{array}{l}\text { Lost } \\
\text { Mean }\end{array}$ & Remark \\
\hline $\begin{array}{l}\text { Socio-cognitive } \\
\text { Skills training }\end{array}$ & 15 & 89.25 & 67.25 & 22.0 & Effective \\
Control & 17 & 90.36 & 79.09 & 10.27 & \\
\hline
\end{tabular}

Table 1 indicates that the adolescents treated with socio-cognitive training technique had pre-test mean score of 89.28 and post-test mean score of 67.25 with lost mean 22. 0 in their aggressive behaviour, while those in the control group who received conventional counselling had pre-test mean score of 90.36 and post- 
test mean score of 79.09 with lost mean 10.27, with post-test mean score of 67.25 which is below the norm of 70.27 , socio-cognitive training technique is effective in reducing aggressive behaviour among adolescents.

\section{Research Question 2}

What is the effectiveness of Socio-cognitive training on the aggressive behaviours of male and female secondary school students?

Table 2: Pre-test and Post-test aggression behaviour mean scores of male and female secondary school adolescents treated with socio-cognitive training skills training $($ Norm $=70.27)$

\begin{tabular}{lclcccc|}
\hline Gender & N & Pretest Mean & \multicolumn{2}{c}{ Post test Mean } & LostMean & Remarks \\
Male & 9 & 89.60 & 66.40 & 23.2 & Effective \\
Female & 6 & 92.0 & 68.67 & 23.33 & Effective & \\
\hline
\end{tabular}

Table 2 indicates that the male adolescents treated with sociocognitive training technique had pre-test mean score of 89.60 and post-test mean score of 66.40 with lost mean 23.2 in their aggressive behaviour, while the female students had pre-test mean score of 92.0 and post-test mean score of 68.67 with a lost mean of 23.33. Sociocognitive skills training is effective in reducing aggressive behaviour of both male and female secondary school adolescents Nevertheless, the lost mean of 23.33 for female students is slightly above those of the male students.

\section{Testing the Null Hypotheses \\ Null Hypothesis 1}

The effect of socio-cognitive training technique on secondary school adolescents' aggressive behaviours will not be significant when compared with those who received conventional counselling using their posttest mean scores. 
Anagbogu, Nwankwo \& Azuji: The effect of Socio-Cognitive ...

Table 3: ANCOVA on the aggressive behaviour post-test mean scores of adolescents treated with socio-cognitive training technique and those who received conventional counselling

\begin{tabular}{lcccccc} 
Source of variation & SS & df & MS & Cal. F & Pvalue & P $\leq 0.05$ \\
\hline Corrected Model & 1055.550 & 2 & 527.775 & & & \\
Intercept & 87.162 & 1 & 87.162 & & & \\
Pre-test & 406.170 & 1 & 406.170 & & & \\
Treatment Model & 119.379 & 1 & 119.379 & 4.52 & .049 & $\mathrm{~S}$ \\
Error & 422.239 & 27 & 26.390 & & & \\
Total & 105818.000 & 32 & & & & \\
\hline Corrected Total & 1477.789 & 31 & & & & \\
\hline
\end{tabular}

Table 3 shows that at 0.05 level of significance, $1 \mathrm{df}$ numerator and $31 \mathrm{df}$ denominator, the calculated $\mathrm{F}$ is 4.52 with Pvalue of 0.049 which is less than 0.05 . Therefore, the first null hypothesis is rejected. So, the effect of Socio-cognitive training technique on secondary school adolescents' aggressive behaviour is significant.

\section{Null Hypothesis 2}

There is no significant difference in the effectiveness of sociocognitive training technique on the aggressive behaviours of male and female adolescents using their posttest mean scores.

\section{Table 4: ANCOVA on the post-test aggressive behaviour mean scores of male and female adolescents treated with socio-cognitive training technique}

\begin{tabular}{lrrllll} 
Source of variation & \multicolumn{1}{c}{ SS } & df & MS & Cal. F Pvalue & P $\leq 0.05$ \\
\hline Corrected Model & 407.340 & 2 & 203.670 & & \\
Intercept & 0.362 & 1 & 0.362 & & \\
Pre-test & 397.707 & 1 & 397.707 & & \\
Treatment Model & 2.333 & 1 & 2.333 & 0.06 & 0.82 & NS \\
Error & 206.160 & 13 & 41.232 & & \\
Total & 36794.000 & 15 & & & \\
\hline Corrected Total & 613.500 & 14 & & & \\
\hline
\end{tabular}


Table 2 reveals that at 0.05 level of significance, $1 \mathrm{dfnumerator}$ and $14 \mathrm{df}$ denominator, the calculated F is 0.06 with Pvalue of 0.82 which is greater than 0.05. Therefore, the fourth null hypothesis is accepted. So, the difference in the effectiveness of socio-cognitive training technique on male and female secondary school adolescents' aggressive behaviours is not significant.

\section{Discussion}

Findings of this study were discussed based on the following themes:

- Effect of Socio-Cognitive Skills Training on aggressive secondary school adolescents.

- Difference in the effects of Socio-Cognitive Skills Training on aggressive male and female secondary school adolescents.

\section{Effect of Socio-Cognitive Skills Training on Aggressive Secondary School Adolescents}

Findings from the study reveal that Socio-cognitive skills training (SCST) technique is effective on aggressive secondary school adolescents. What this means is that the socio-cognitive skills training was able to have reasonable impact on the adolescents enough to control the aggressive behaviours that could result in both physical and psychological harm to oneself, others or objects in the environment. This finding is in agreement with Horan, et al. (2011), whose study showed that a targeted social cognitive training led to improvements in social cognition among outpatients with psychosis. Social cognition is a skill that focuses on the role that cognitive processes play in social interactions from which aggressive behaviours could arise. The SCST group in 'that essence demonstrated greater improvements over time than those in the conventional group. The reason being that, those in SCST group possibly recorded more improvement in their social cognitive domain of emotional processing and in emotion management. So, they are better placed to process information, relate with others in a friendly way and manage their emotion enough to restrain themselves from acting aggressive even when they seemed provoked. 
Anagbogu, Nwankwo \& Azuji: The effect of Socio-Cognitive ...

In addition, the findings of the study reveal that the effect of socio-cognitive skills training on aggressive secondary school adolescents is significant. What this implies is that the effect of socio-cognitive skills training on aggressive secondary school adolescents is substantial. This finding of the study is consistent with Chen, Wei, Deng and Sun (2017), whose study investigated the effects of Cognitive Training on cognitive abilities and everyday function, and observed that cognitive training significantly improved targeted cognitive functions and everyday problem-solving performance in all the intervention groups. Similarly, Van-Manen, Prins and Emmelkamp's (2005) outcome of the treatment conditions indicated; a significant increase in appropriate social behaviour, social cognitive skills, and self-control and a significant decrease in aggressive behaviour. The reason for Van-Manen, Prins and Emmelkamp's findings, which is also applicable to the finding of this current study perhaps, is that through socio-cognitive skills training, the participants were able to acquire information that allowed them to reason about the situation that surround their aggressive behaviour and determine how to behave appropriately. These according to Rao, Beidel and Murray (2008), are behavioural clues that could help persons who have difficulties relating to other people due to poor social perceptions. Since aggressive behaviour has to do with cognitive functions of an individual, when such persons are faced with social situations for which they are unprepared emotionally and cognitively, they tend to respond with aggression. Socio-Cognitive Skills Training consequently enhanced the adolescents' ability to avoid such aggressive situations and solve problems non-violently by enhancing their social relationships with peers and teach them how to interpret some behavioural cues to improve their conflict-resolution skills. It is believed that the changing of their thought processes possibly resulted in altering and modifying their aggressive response which reflected in the findings of this study.

\section{Difference in the effects of Socio-Cognitive Skills Training on Aggressive Male and Female Secondary School Adolescents}

Findings of the study revealed that the difference in the effects of Socio-Cognitive Skills Training on aggressive male and female 
secondary school adolescents is not significant. This means that the treatment using socio-cognitive skills technique has similar effects on both male and female secondary school adolescents. This finding is rather surprising, since male and female are known to differ in personality characteristics, both biologically and in gender role socialisation. Nevertheless, the findings of this current study showed that Socio-Cognitive Skills Training as indicated has no gender dimension, since its effect cuts across genders, having near matching effects on both the male and female adolescents.

Although the researchers had expected a significant gender difference in favour of the male participants, the reason being that males are assumed to possess higher cognitive abilities than females. Nevertheless, the results of this study voided the assumption and supported the supposition that gender differences in response to the socio-cognitive treatment are non-significant or very small. The findings of the study thereby assert that both male and female secondary school adolescents have opportunity to overcome their aggressive behaviour through socio-cognitive skills training.

\section{Conclusion}

Based on the findings of this study, the following conclusions are made: That Socio-cognitive skills training and Self-instruction technique have significant effect on aggressive male and female secondary school adolescents in reducing their aggressive behaviour.

\subsection{Implications of the Study}

Based on the finding of this study, the implication is that since the socio-cognitive skills training is effective on aggressive secondary school adolescents; both the school guidance counsellors and therapists are now presented the opportunity to explore the use of these techniques for modifying the aggressive behaviours of secondary school students. Another implication of this study is that the findings would stimulate further research and will most likely serve as a reference point to other researchers.

\section{Recommendations}

Based on the findings of this study, the following recommendations are made: 
Anagbogu, Nwankwo \& Azuji: The effect of Socio-Cognitive ...

1. Socio-Cognitive Skills Training is an effective therapeutic technique for reducing aggressive behaviours among secondary school adolescents. Therefore, practicing counsellors and therapist should adopt the use of the technique in counselling and therapy among secondary school students to modify and treat aggressive behaviour.

2. The school teachers should be guided by the guidance counsellors to use the aggressive behaviour scale on their student for early identification of it.

\section{*Mercy Aku Anagbogu}

Professor, Department of Guidance and Counselling, Nnamdi Azikiwe University, Anambra State, Nigeria.

ma.anigbogu@unizik.edu.ng

\section{*Christopher Amobi Nwankwo}

Professor of Counselling Psychology, Department of Guidance and Counselling, Nnamdi Azikiwe University, Anambra State, Nigeria. ca.nwankwo@unizik.edu.ng

\section{*Ifeanyi Mathew Azuji}

PhD Research Scholar, Department of Guidance and Counselling, Nnamdi Azikiwe University, Anambra State, Nigeria. ifeanyichukwua@gmail.com 


\section{References}

Agbakwuru, C. \&Ugwueze, S. (2014). Effect of assertiveness training on resilience among early-adolescents.European Scientific Journal, 8, (10), 69-84.

Aluede, O. (2011). Managing bullying problems in Nigerian secondary schools.Retrieved: Microsoft Corporation.

Horan, W.P., Kern, R.S., Tripp, C., Hellemann, G., Wynna, J.K., Bell, M., Marder, S.R., Green, M.F. (2011). Efficacy and specificity of Social Cognitive Skills Training for outpatients from www.ncsu.edu/

Babakhani, N. (2011). The effects of social skills training on selfesteem and aggression male adolescents.Procedia - Social and Behavioural Sciences, 30, 1565-1570.

Centers for Disease Control and Prevention (2013).Youth violence national and state statistics at a glance. Retrieved from http://www.cdc.gov/

Gould, C., Grant, Gould, J. L., and Jensen, R. A.(2008). "Aggression." Microsoft Meyers, L. (2016). Fertile grounds for bullying. Counselling today, Journal of American Counselling Association, 58(11), 27-35.

Horan, W.P., Kern, R.S., Tripp, C., Hellemann, G., Wynna, J.K., Bell, M., Marder, S.R., Green, M.F. (2011).Efficacy and specificity of Social Cognitive Skills Training for outpatients.from www.ncsu.edu/

Jean, L., Bergeron, M-E., Thivierge, S., \&Simard, M. (2010). Cognitive intervention programs for individuals with mild cognitive impairment: Systematic review of the literature. Journal of the American Geriatrics Society, 18, 281-296.

Kern, R.S., Glynn, S.M., Horan, W.P., Marder, S.R. (2009). Psychosocial treatments to promote functional recovery in schizophrenia.Schizophrenia Bulletin, 35.

Meyers, L. (2016). Fertile grounds for bullying. Counselling today, Journal of American Counselling Association, 58(11), 2735.

Nnodum, B.I. (2010). Relative effectiveness of assertive training, modelling and their combination in the reduction of isolate behaviour in children.Edo Journal of Counselling, 3(1), 1 15 
Anagbogu, Nwankwo \& Azuji: The effect of Socio-Cognitive ...

Shekarey, A.; Ladarni and Rostami (2013).Relationship between social intelligence and students aggressive behaviours. Retrieved from www.macrothink.org

Terzian, M., Hamilton, K., \& Ling, T. (2011). What works for acting-out (externalizing) behaviour: Lessons from experimental evaluations of social interventions. Child Trends Fact Sheet.Retrieved from www.childtrends.org.

World Health Organisation (2014).Maternal, newborn, child and adolescent health. Retrieved from http://www.who.int/

Zirpoli, T.J. (2014). Behaviour Management: application for teachers. Pearson Allyn Bacon Prentice Hall. Retrieved September 21, 2015 from http//:www.education.com/ 